\title{
Complacência estética e satisfação do querer na metafísica do belo de Schopenhauer
}

\author{
Aesthetic complacency and satisfaction of will in Schopenhauer's metaphysic of the \\ beauty
}

\section{Jarlee Oliveira Silva Salviano}

Resumo: Seguindo os passos de Kant, Schopenhauer erige sua Metafísica do belo a partir da concepção de arte "desinteressada". O conhecimento determinado por motivos proporciona ao espectador da arte o "excitante" e a mera satisfação empírica, mas não o belo ou o sublime. O gênio, representação mais potente e eficaz da subjetividade pura do conhecimento, é descrito no Livro III de O mundo como vontade e representação de modo aparentemente ambíguo: como o Willenlos (isento de vontade), como aquele "livre da tempestade das paixões" e do "ímpeto dos desejos". Mas, ao mesmo tempo, como aquele "submetido a afetos veementes e paixões irracionais". No entanto, trata-se, na vivência estética do gênio ou do contemplador da arte, de um prazer desinteressado, de uma complacência de outra ordem que a do homem do senso comum e de ciência. O artigo procura, então, analisar o conceito de complacência ou satisfação estética em Schopenhauer e seu enraizamento na filosofia de Kant.

Palavras-chave: Schopenhauer; Kant; Desinteresse; Complacência

\begin{abstract}
Following in the footsteps of Kant, Schopenhauer builds his Metaphysics of the beauty from the conception of art "disinterested". Knowledge determined by motives gives to the spectator of art the "exciting" and the mere empirical satisfaction, but not the beauty or the sublime. The Genius, most potent and effective representation of the Pure Subjectivity of Knowledge is described in the Book III of The world as will and representation in an apparently ambiguous way: as the Willenlos (free of will), like that free of the storm of the passions and the impetus of desires. But at the same time as that subjected to vehement affections and irrational passions. However, it is, in the aesthetic experience of the genius or the contemplator of art, a disinterested pleasure, a complacency of another order than that of the man of common sense and science. The article then seeks to analyze Schopenhauer's concept of aesthetic complacency or satisfaction and its roots in Kant's philosophy.
\end{abstract}

Keywords: Schopenhauer; Kant; Disinterest; Complacency

Partindo da distinção kantiana entre fenômeno e coisa-em-si, e da teoria das formas eidéticas de Platão, Schopenhauer constrói sua filosofia da arte centralizada na cisão do agente estético em, por um lado, uma subjetividade metafísica e, por outro lado, a individualidade empírica. Outra distinção importante consiste na diferenciação estratégica

\footnotetext{
*Professor de Filosofia na Universidade Federal da Bahia, Salvador, BA. E-mail: jarlee.salviano@ufba.br
} 
entre representação e fenômeno (efetivação da Vontade noumênica tecida pelas formas do tempo, espaço e causalidade). As Ideias platônicas, por exemplo, mediação ontológica entre a Vontade e os fenômenos, são representações, mas constituídas de uma única forma: a de ser-objeto-para-um-sujeito. Elas são, conforme neologismo postulado por ele, objetidade (Objektität) da vontade - o termo "objetividade" (Objektivität) será usado em sua obra exclusivamente para a referência à forma de conhecimento do gênio, a orientação objetiva do espírito, não degradada pelas formas sensíveis do conhecimento. O primeiro tem, portanto, um sentido ontológico; o segundo, epistemológico.

Diante desse panorama bem conhecido da estética schopenhaueriana (em que pese a inadequação desta expressão em relação à preferência do autor por “metafísica do belo”), o presente escrito faz algumas reflexões, em vista da aproximação com Kant, sobre alguns conceitos-chave deste andar do edifício filosófico do pessimista irresoluto. Seguiremos como fio condutor o conceito de complacência ou satisfação estética.

Tanto em Kant quanto em Schopenhauer, o fundamento da valoração estética, assim como da valoração moral, está relacionado ao modo de satisfação proporcionado ao sujeito na sua relação com a representação do objeto.

Vejamos como isto se dá em Kant.

No início da Analítica do belo de sua Crítica da faculdade de julgar, Kant apresenta a diferença entre a forma de satisfação (ou complacência, Wohlgefallen) ${ }^{1}$ relacionada ao sujeito empírico, ao sujeito estético e ao sujeito ético. Diz o filósofo: "Cada um tem de reconhecer que aquele juízo sobre beleza, ao qual se mescla o mínimo interesse, é muito faccioso e não é nenhum juízo-de-gosto puro" ${ }^{2}$. Em oposição à forma de complacência do sujeito empírico (a satisfação do prazer oriundo das sensações, que é sempre subjetivo, portanto, interessado) pode-se afirmar que no juízo de gosto se trata de um prazer desinteressado, objetivo, mediado pela reflexão. A complacência sensível, portanto, o agradável, é sempre interessada, ligada a um prazer subjetivo, ao modo como somos afetados pelo objeto e o sentimento de prazer que advém desta percepção.

Por outro lado, o sujeito ético é também interessado, mas seu interesse não está ligado às inclinações (daí nenhuma objetividade e valor moral pode resultar), mas se direciona ao conceito de lei moral apenas, à pura normatividade transcendental a priori dada pela razão. Trata-se de um interesse objetivo, ao passo que o sujeito empírico, impulsionado pelas inclinações, liga-se ao objeto com interesse subjetivo. Neste caso, ainda que esteja conforme à lei, sua ação não tem qualquer valor moral, pois se serve dela apenas como meio para seus fins egoístas. "Somente através do que o homem faz sem

\footnotetext{
${ }^{1} \mathrm{Na}$ sua tradução da Crítica da faculdade do juízo, Valério Rohden fundamenta bem sua opção para verter Wohlgefallen por complacência, mostrando que em alguns escritos, como na Antropologia, Kant mesmo fez seguir à expressão Wohlgefallen, entre parênteses, o latim complacentia (na própria Crítica da faculdade do juízo é utilizado o termo Komplazenz, em substituição a Wohlgefallen).

${ }^{2}$ KANT, Crítica da faculdade do juízo, p. 50.
} 
consideração do gozo”, diz Kant, “em inteira liberdade e independentemente do que a natureza também passivamente poderia proporcionar-lhe, dá ele um valor absoluto à sua existência enquanto existência de uma pessoa; e a felicidade, com a inteira plenitude de sua amenidade (Annehmlichkeit), não é de longe um bem incondicionado"3.

Em suma, são três as formas de satisfação relativamente ao prazer ou desprazer, ou seja, três formas de complacência: o agradável (Angenehm), a satisfação advinda das sensações do sujeito empírico; o bom (Gut), a ação motivada tão somente pela lei moral, sem qualquer influência das inclinações; e o belo (Schön), a única complacência desinteressada, diferentemente das duas primeiras. O agradável é aquilo que deleita (vergnügt); o bom é aquilo que é estimado (geschätzt); e o belo é o que apraz (gefällt). Entre estes três, "única e exclusivamente o do gosto pelo belo é uma complacência desinteressada e livre; pois nenhum interesse, quer o dos sentidos, quer o da razão, arranca aplauso"4.

A distinção entre o bom e o agradável já se apresenta, de fato, na Fundamentação da metafísica dos costumes:

Praticamente bom é porém aquilo que determina a vontade por meio de representações da razão, por conseguinte, não por causas subjetivas, mas objetivamente, quer dizer, por princípios que são válidos para todo o ser racional como tal. Distingue-se do agradável, pois que este só influi na vontade por meio da sensação em virtude de causas puramente subjetivas que valem apenas para a sensibilidade deste ou daquele, e não como princípio da razão que é válido para todos ${ }^{5}$.

Pode-se ainda perceber nesta tríade kantiana a expressão clara de seu sistema Crítico: do sujeito empírico inserido na fenomenalidade (como ser natural, e da forma de conhecimento a ele adequada: sempre interessada) tratou a Crítica da razão pura. Do sujeito ético, e sua relação respeitosa com a lei moral imperativa inscrita na racionalidade, tratou a Crítica da razão prática. E, finalmente, do sujeito do juízo de gosto, desinteressado, tratou a Crítica da faculdade do juízo.

Vejamos como se desenha, no Livro III de O mundo como vontade e representação, de Schopenhauer, esta arquitetura de sua metafísica do belo relativamente à concepção de satisfação do sujeito na sua relação com o objeto (a arte ou a bela natureza), em comparação às formas de satisfação do sujeito empírico e do sujeito ético. Perceberemos que as traduções disponíveis deste momento da obra schopenhaueriana, por não levarem em conta esta aproximação com Kant (sabemos da importância da terceira Crítica deste para a concepção de conceitos fundamentais da estética de Schopenhauer, como o belo e o

\footnotetext{
${ }^{3}$ Idem, p. 53.

${ }^{4}$ Idem, p. 55.

${ }^{5}$ KANT, Fundamentação da metafísica dos costumes, p. 124.
} 
sublime), dificultam ao leitor o acesso a certas nuances desta discussão sobre a satisfação estética.

De início, já no primeiro parágrafo do referido terceiro Livro, Schopenhauer estabelece a distinção entre sujeito e indivíduo. O segundo é a subjetividade empírica, manifestação fenomênica da Vontade noumênica; o primeiro é a subjetividade que equivalerá ao nível da transcendentalidade de Kant, mas, com a ajuda da doutrina das Ideias de Platão, este sujeito do conhecimento schopenhaueriano é a objetidade adequada da Vontade, da qual o indivíduo empírico é uma mera manifestação no tempo. Trata-se de uma espécie de subjetividade desindividualizada, "olho cósmico" (Weltauge) da Vontade, dirá o filósofo. É este sujeito puro do conhecimento que acessa as Ideias na atividade estética, na criação e na contemplação: “caso as Ideias devam se tornar objeto de conhecimento, isso só pode ocorrer pela supressão da individualidade no sujeito cognoscente” (W I, 236). A arte é, assim, autoconhecimento da Vontade.

Do mesmo modo, estabelece a diferença entre o fenômeno (Erscheinung) empírico e a representação (Vorstellung), para ser mais preciso, um tipo específico de representação: a Ideia platônica. As Ideias são representações, mas não são fenômenos (estes são espaçotemporais, sob a regência da causalidade). Assim, pertence às Ideias uma única forma, a do ser-objeto-para-um-sujeito (Objekt-für-ein-Subjekt-sein).

Como indivíduos, na intuição mediada por um corpo, o conhecimento está a serviço da Vontade. Não percebe as coisas como são em si, mas nas suas relações com outras coisas, através do princípio de razão. E na relação das coisas com sua própria corporeidade, na mediação com o tempo, o espaço e a causalidade, "pois somente mediante estes o objeto é INTERESSANTE para o indivíduo, isto é, possui uma relação com a Vontade” (W I, 244, destaque do autor).

Eis, então, que surge o estado estético, assim descrito pelo filósofo:

Quando, elevados pela força do espírito, abandonamos o modo comum de consideração das coisas, cessando de seguir apenas suas relações mútuas conforme o princípio de razão, cujo fim último é sempre a relação com a própria vontade; logo, quando não mais consideramos o Onde, o Quando, o Porquê e o Para Quê das coisas, mas única e exclusivamente o seu QUÊ [...] a gente se PERDE por completo nesse objeto, isto é, esquece o próprio indivíduo, o próprio querer, e permanece apenas como claro espelho do objeto [...] justamente por aí, ao mesmo tempo, aquele que concebe na intuição não é mais indivíduo, visto que o indivíduo se perdeu nessa intuição, e sim o atemporal PURO SUJEITO DO CONHECIMENTO destituído de Vontade e sofrimento (W I, 246).

${ }^{6}$ Em caso de não sinalização em contrário, todos os destaques em caixa alta nas citações são do autor. 
Diferentemente da arte, obra do gênio (o suprassumo da subjetividade pura do conhecimento), a ciência incessantemente segue a cadeia causal do princípio de razão: "de cada fim alcançado é novamente atirada mais adiante, nunca alcançando um fim final, ou uma satisfação completa” (W I, 253) ${ }^{7}$. O gênio é o único a alcançar um esquecimento completo de si mesmo:

[...] a GENIALIDADE nada é senão a OBJETIVIDADE (Objektivität) mais perfeita, ou seja, orientação objetiva do espírito, em oposição à subjetiva que vai de par com a própria pessoa, isto é, com a vontade. Por consequência, a genialidade é a capacidade de proceder de maneira puramente intuitiva, de perder-se na intuição e afastar por inteiro dos olhos o conhecimento que existe originariamente apenas a serviço da Vontade ou seja, de seu interesse, querer e fins (W I, 236).

No homem comum, esse produto de fábrica da natureza, diz ele, predomina a sujeição à Vontade, e o conhecimento e a ação determinados por motivos (Motive) - toda mola propulsora empírica, cognitiva ou prática. No entanto, paradoxalmente, o gênio é descrito constantemente pelo filósofo ao mesmo tempo como sujeito desinteressado e também como aquele submetido a afetos veementes e paixões irracionais, dada esta proximidade da intuição genial às cercanias da Vontade como coisa-em-si, fonte de todo desassossego e sofrimento - daí sua natureza melancólica. Em contraposição ao tormento (Qual), das mazelas do homem cotidiano, o homem de gênio vive a inescapável presença do sofrimento (Leiden) advindo das entranhas da noumenalidade.

De todo modo, seja na criação do gênio, seja na contemplação da obra de arte ou da bela natureza, há um contentamento, uma satisfação vetada ao indivíduo fenomênico e possível apenas ao sujeito estético. Esta passagem do terceiro Livro de sua obra magna (em que aparece o primeiro relato de seu pessimismo - no Livro anterior, o conflito das forças na natureza indica o aspecto trágico de sua filosofia, certamente apreciado por Nietzsche) dá conta desta tese:

Desses dois componentes do modo de conhecimento estético [Ideia e Sujeito Puro do Conhecimento] resulta também a SATISFAÇÃO (Wohlgefallen) despertada pela consideração do belo e, na verdade, satisfação mais em face de um ou de outro, conforme o objeto da contemplação [...]. Todo QUERER nasce de uma necessidade, portanto de uma carência, logo, de um sofrimento. A satisfação (Erfüllung) põe um fim ao sofrimento; todavia, contra cada desejo satisfeito permanecem pelo menos dez que não o são. Ademais, a nossa cobiça dura muito, as nossas exigências não conhecem limites; a satisfação (Erfüllung), ao contrário, é breve e módica.

\footnotetext{
${ }^{7}$ Platão e Aristóteles são as personagens, entre os antigos, escolhidas por Schopenhauer para representar o gênio e o cientista, respectivamente.
} 
Mesmo a satisfação (Befriedigung) final é apenas aparente, o desejo satisfeito (erfüllt) logo dá lugar a um novo: aquele é um erro conhecido, este um erro ainda desconhecido. Objeto algum alcançado pelo querer pode fornecer uma satisfação (Befriedigung) duradoura, sem fim, mas ela se assemelha sempre apenas a uma esmola atirada ao mendigo, que torna sua vida menos miserável hoje, para prolongar seu tormento (Qual) amanhã - Daí, portanto, deixar-se inferir o seguinte: pelo tempo em que o querer preenche a nossa consciência, pelo tempo em que estamos entregues ao ímpeto dos desejos com suas contínuas esperanças e temores, por conseguinte, pelo tempo em que somos sujeito do querer, jamais obtemos felicidade duradoura ou paz. E em essência é indiferente se perseguimos ou somos perseguidos, se tememos a desgraça ou almejamos o gozo: o cuidado pela Vontade sempre exigente, não importa em que figura, preenche e move continuamente a consciência. Sem tranquilidade, entretanto, nenhum bem-estar verdadeiro é possível. O sujeito do querer, consequentemente, está sempre atado à roda de Íxion que não cessa de girar, está sempre enchendo os tonéis das Danaides, é o eternamente sedento Tântalo (W I, 266).

Infelizmente a tradução de Jair Barboza, ao verter estes conceitos distintos igualmente por "satisfação", não ajuda o leitor a perceber uma importante conceituação de Schopenhauer (a tradução de Maria Lúcia Cacciola, da coleção Os Pensadores, também não atenta para esta distinção): diferentemente de Kant, para quem o termo Wohlgefallen foi utilizado para significar a satisfação de um modo geral (a complacência em suas três configurações), em Schopenhauer o conceito Wohlgefallen serve ao filósofo exclusivamente para a designação da satisfação estética. Por outro lado, a satisfação empírica (o malogrado contentamento do sujeito do querer) é grafada como Erfüllung ou Befriedigung. Mais adiante, no quarto Livro (noutra impressionante apresentação de seu pessimismo ontológico) encontramos este comentário sobre a satisfação fenomênica:

Há muito reconhecemos esse esforço, constitutivo do núcleo, do em-si de toda coisa, como aquilo que em nós mesmos se chama VONTADE e aqui se manifesta da maneira mais distinta na luz plena da consciência. Nomeamos SOFRIMENTO a sua travação por um obstáculo, posto entre ela e o seu fim passageiro; ao contrário, nomeamos SATISFAÇÃO (Befriedigung), bemestar, felicidade, o alcançamento do fim [...] Pois todo esforço nasce da carência, do descontentamento com o próprio estado e é, portanto, sofrimento pelo tempo em que não for satisfeito (befriegt); nenhuma satisfação (Befriedigung), todavia é duradoura, mas antes sempre é um ponto de partida de um novo esforço, o qual, por sua vez, vemos travado em toda parte de diferentes maneiras, em toda parte lutando, e assim, portanto, sempre como sofrimento: não há nenhum fim último do esforço, portanto não já nenhuma medida e fim do sofrimento (W I, 399). 
Em alguns casos, como na passagem do terceiro Livro em que analisa a hierarquia dos sentidos a partir de sua facilitação ou dificultação para a vivência estética (a visão estando no topo da hierarquia), Schopenhauer lança mão do termo Angenehm, utilizado por Kant (citado nesta passagem) para designar a complacência empírica, o agradável: "O odor, entretanto, é sempre agradável (Angenehm) ou desagradável; o paladar ainda mais. Portanto, estes dois últimos sentidos são os mais intimamente ligados à vontade. Eis por que sempre foram chamados de sentidos menos nobres e, por Kant, de sentidos subjetivos" (W I, 271).

Enfim, no mesmo sentido de Erfüllung ocorre também em Schopenhauer o termo Gewährung, como no parágrafo 40 do terceiro Livro, em que faz uma análise do excitante enquanto aquilo que se opõe diametralmente ao sublime, pois enquanto este eleva o espectador da terrível ameaça da natureza desfavorável à vontade, o excitante desce o sujeito estético da pura contemplação exigida (tanto no aspecto positivo, objetos que excitam e atraem a vontade; quanto do negativo, o "repugnante", especialmente reprovável na arte). "Entendo sob este termo", afirma Schopenhauer, referindo-se ao excitante, "aquilo que estimula a vontade, apresentando-se diretamente à sua satisfação (Gewährung), ao seu preenchimento (Erfüllung) (W I, 280)”.

Ademais, outra diferença entre os dois autores diz respeito ao conceito de interesse. Para Kant a única atividade do sujeito absolutamente desinteressada é o juízo de gosto estético. Para Schopenhauer tanto a fruição da arte como a ação moral podem ser desinteressadas: no fenômeno da compaixão (na ética de Schopenhauer: o critério para o julgamento moral da ação) o agente já está despido de sua individualidade, age tão somente motivado pela dor alheia, sem qualquer resquício de egoísmo, portanto desinteressadamente. Tendo rejeitado veementemente a possibilidade do respeito pela lei moral (toda legislação imperativa tem um fundamento teológico, portanto se assenta no medo ou esperança de recompensa, no egoísmo), a única motivação que conduz a uma valoração moral positiva, para ele, é o esquecimento de si e a inserção desinteressada no infortúnio alheio, para amenizá-la ou suprimi-la. Mas concordam também as duas filosofias em que todo eudaimonismo fundado na motivação empírica, nas sensações do sujeito empírico, leva ao interesse e exclui toda possibilidade de valoração positiva, ética ou estética.

Nas pesquisas sobre Schopenhauer no Brasil, há dois artigos elucidativos sobre a questão do desinteresse em Schopenhauer que podem vir em apoio desta discussão. O artigo "O conceito de interesse”, de Maria Lúcia Cacciola, e o artigo “Desinteresse e comprazimento estético: considerações acerca da apreciação da estética kantiana por Schopenhauer face às de Hegel e Heidegger”, de Dax Moraes. O último se apresenta, afirma o autor, como uma extensão da defesa de Schopenhauer diante das críticas de Heidegger, realizada pelo artigo anterior. 
A crítica heideggeriana busca mostrar que houve uma distorção da terceira Crítica kantiana por parte de Schopenhauer ao inserir o caráter ético na estética do filósofo de Königsberg, visando a um niilismo ascético de desapego do mundo, "uma espécie de

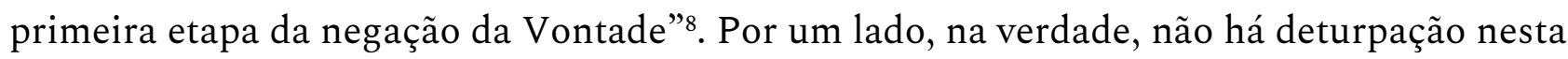
interpretação de Schopenhauer sobre o desinteresse, defende Cacciola: "A sua leitura do desinteresse é bem mais radical, na medida em que é por meio do belo desinteressado que se torna possível um conhecimento verdadeiro, não de um algum referente oculto, de algo real, mas sim daquilo que é ideal" ". A preocupação de Schopenhauer é a de excluir qualquer presença de elemento racional abstrato na contemplação estética que, segundo ele, haveria na concepção kantiana de juízo reflexionante e a sua pretensa universalidade. Se há, por outro lado, uma aproximação entre a ética e a estética em Schopenhauer, uma não subsume a outra: pode-se dizer, além disso, que é a estética que fundamenta a ética, pois esta também lidará com o desinteresse, ao apresentar a compaixão desinteressada como fundamento da moral.

É curioso notar que, a despeito da crítica de Heidegger, e da aproximação aqui defendida entre Kant e Schopenhauer, é justamente este segundo que lamenta no primeiro a mistura malsã de ética e estética quando, ao tratar do sublime matemático (reconhecendo a origem kantiana da nomenclatura), afirma seu distanciamento dele "na explicitação da essência íntima dessa impressão, isentando-a seja de reflexões morais, seja de hipóstases da filosofia escolástica” (W I, 278). Mas, um pouco adiante, acaba se contradizendo: “Sim, também ao ético se deixa transmitir a nossa explanação do sublime, a saber, àquilo que se descreve como caráter sublime” (W I, 279) - de quem considera os homens de modo puramente objetivo.

Por outro lado, Dax Moraes, em seu artigo, procura mostrar que a indisposição de Heidegger em relação a Schopenhauer é artificiosa, que somente uma incompreensão por parte de Heidegger não o permitiu perceber que também em Schopenhauer o fenômeno estético se explica a partir desta tomada do objeto a partir do florescimento de seu caráter objetivo, independente de toda apropriação utilitária. Mas vai além disso. Em Heidegger, "portanto, é na medida em que deixamos que o objeto seja por-si que sua beleza aparece enquanto dignidade própria, podendo-se dizer que nisto consiste o que ele denomina 'relação real com o objeto', ou seja, o modo próprio da relação sujeito-objeto, na qual nenhum dos dois se retira, como teria dito Schopenhauer"10. Ao passo que em Schopenhauer, também em Kant, não se trata mais da manutenção de certa relação real entre sujeito e objeto, mas de sua superação, de sua subsunção.

\footnotetext{
${ }^{8}$ CACCIOLA, O conceito de interesse, p. 5.

${ }^{9}$ Idem, p. 9.

${ }^{10}$ MORAES, Desinteresse e comprazimento estético: considerações acerca da apreciação da estética kantiana por Schopenhauer face às de Hegel e Heidegger, p. 156.
} 


\section{Referências}

CACCIOLA, Maria Lúcia. O conceito de interesse. Cadernos de Filosofia Alemã, São Paulo, Vol. 5, 1999, pp. 5-15.

KANT, Immanuel. Crítica da faculdade do juízo. Trad. Valério Rohden e António Marques. Rio de Janeiro: Forense Universitária, 1995.

KANT, Immanuel. Fundamentação da metafísica dos costumes. Trad. Paulo Quintela. São Paulo: Abril Cultural, 1980 (Col. Os Pensadores).

MORAES, Dax. Desinteresse e comprazimento estético: considerações acerca da apreciação da estética kantiana por Schopenhauer face às de Hegel e Heidegger. O que nos faz pensar, Rio de Janeiro, Vol. 28, 2010, p. 145-167.

SCHOPENHAUER, Arthur. Sämtliche Werke. Textkritisch bearbeitet und herausgegeben von Wolfgang Frhr. Löhneysen. Darmstadt: Wissenschaftliche Buchgesellschaft, 1968.

SCHOPENHAUER, Arthur. O mundo como vontade e como representação (W I). Trad. Jair Barboza. São Paulo: Editora da Unesp, 2005.

SCHOPENHAUER, Arthur. O mundo como vontade e representação. Livro III. Trad. Maria Lúcia Mello e Oliveira Cacciola. São Paulo: Abril Cultural, 1980 (Col. Os Pensadores).

SCHOPENHAUER, Arthur. Sobre o fundamento da moral. 2ª ed. Trad. Maria Lúcia Mello e Oliveira Cacciola. São Paulo: Martins Fontes, 2001. 